\title{
Connecting European snow cover variability with large scale atmospheric patterns
}

\author{
E. Bartolini ${ }^{1}$, P. Claps ${ }^{1}$, and P. D’Odorico ${ }^{2}$ \\ ${ }^{1}$ Dipartimento di Idraulica, Trasporti e Infrastrutture Civili, Politecnico di Torino, Corso Duca degli Abruzzi, \\ 10129 Torino, Italy \\ ${ }^{2}$ Department of environmental sciences, University of Virginia, 291 McCormick Road, P.O. Box 400123, \\ Charlottesville, VA, USA
}

Received: 23 February 2010 - Revised: 24 March 2010 - Accepted: 6 July 2010 - Published: 1 September 2010

\begin{abstract}
Winter snowfall and its temporal variability are important factors in the development of water management strategies for snow-dominated regions. For example, mountain regions of Europe rely on snow for recreation, and on snowmelt for water supply and hydropower. It is still unclear whether in these regions the snow regime is undergoing any major significant change. Moreover, snow interannual variability depends on different climatic variables, such as precipitation and temperature, and their interplay with atmospheric and pressure conditions. This paper uses the EASE Grid weekly snow cover and Ice Extent database from the National Snow and Ice Data Center to assess the possible existence of trends in snow cover across Europe. This database provides a representation of snow cover fields in Europe for the period 1972-2006 and is used here to construct snow cover indices, both in time and space. These indices allow us to investigate the historical spatial and temporal variability of European snow cover fields, and to relate them to the modes of climate variability that are known to affect the European climate. We find that both the spatial and temporal variability of snow cover are strongly related to the Arctic Oscillation during wintertime. In the other seasons, weaker correlation appears between snow cover and the other patterns of climate variability, such as the East Atlantic, the East Atlantic West Russia, the North Atlantic Oscillation, the Polar Pattern and the Scandinavian Pattern.
\end{abstract}

\section{Introduction}

The cryosphere is the major stock of freshwater resources on Earth (e.g., Dingman, 1994; Chow et al., 1988), and as such it plays an important role in the water cycle, climate dy-

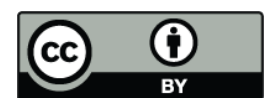

Correspondence to: E. Bartolini (elisa.bartolini@polito.it) namics, human activities and ecosystem functioning (Bonan, 2002). The dynamics of snow accumulation and melting not only drive runoff generation in snow-dominated regions, but also affect the seasonal availability of water resources, that are crucial to the regional economies (e.g. agriculture, winter sports). Moreover, at large scales, snow cover extent and temporal persistence also influence the interaction and feedbacks between the land surface and the atmosphere, due to the effect of albedo on the surface energy balance (e.g., Bonan, 2002; Armstrong and Brun, 2008). Studies on the relation between snowpack and climate have shown that hydrologic conditions of snow-dominated regions are more likely to be affected by climate change (e.g. Adam et al., 2009). It is therefore important to understand the patterns and drivers of seasonal and interannual fluctuation in snow cover extent and temporal persistency (e.g., Popova, 2007; Brown, 2000; Cohen and Entekhabi, 2001; Yoo and D'Odorico, 2002). Gutzler and Rosen (1992) showed that snow cover fluctuations in Europe are particularly strong and related to an atmospheric circulation pattern resembling the North Atlantic Oscillation (NAO). Clark et al. (1999) identified connections between patterns of atmospheric circulation and Eurasian snow cover, and explained them as an effect of the relation existing between the NAO and surface temperatures. In fact, the relation between the NAO and precipitation or temperature has been well documented and understood (e.g., Hurrell, 1995; Bartolini et al., 2009), and could translate into a dependence of snowfall and snow accumulation on the NAO.

The aim of this study is to investigate the interannual variability of snow cover over Europe using spatial and temporal indices obtained with satellite observations. The temporal extension of available satellite data allows us to improve the results of previous studies on trends and fluctuations in snow cover. We seek for relationships between snow indicators and large scale patterns of atmospheric circulation, looking for possible leading mechanism of interactions. The modes of atmospheric variability considered in this analysis

Published by Copernicus Publications on behalf of the European Geosciences Union. 
include the North Atlantic Oscillation (NAO), the Scandinavian Pattern (SCA), the Polar Pattern (POL), the East Atlantic (EA) the East Atlantic West Russia (EA/WR) (Barnston and Livezey, 1987) and the Arctic Oscillation (AO). The AO (Thompson, 2001) is characterized by the opposition of pressure patterns between the high and middle latitudes of the Northern Hemisphere. Its negative phase is associated with high frequencies of cold event over Europe, while positive $\mathrm{AO}$ indices are related to lower than normal pressure over the Northern Pole, higher than normal temperature over Europe and dry conditions on the Mediterranean area.

\section{Data}

Snow cover data from the EASE Grid Weekly Snow Cover and Ice Extent version 3.1 (Armstrong and Brodzik, 2005) were analyzed to characterize the snow season and its spatiotemporal variability. Developed at the National Snow and Ice Data Center (NSIDC, Boulder, Colorado), the database provides snow cover extent from 3 October 1966, and ice extent from 23 October 1978, at a weekly resolution. Snow data are subjected to a quality control (NSIDC Quality control summary) aimed at rectifying misclassification issues (e.g. land pixels above the snow line not classified as snow). With reference to the European continent, we select snow cover data from January 1972 in order to have continuous time series, running until 2006. Even though the declared spatial resolution is $25 \mathrm{~km}$, mapping the data (not shown) some broaderresolution artefacts appear. This fact can be neglected considering the continental scale of the study, but should be taken into account for local scale investigation. The modes of atmospheric variability are quantified using monthly indices, available from the database of the Climate Prediction Center of the National Oceanic and Atmospheric Administration (www.cpc.noaa.gov).

\section{Methods}

Snow cover weekly time series are aggregated at the 12,6 , and 3 months time scales. The 6-months aggregation partitions the year in two periods, respectively the cold (from October to March) and the warm season (from April to September); the 3-months aggregation identifies four seasons: winter (January-March), spring (April-June), summer (JulySeptember) and autumn (October-December). Due to the weekly temporal resolution, it is necessary to identify a criterion to set the beginning of each season. We define as the first winter week the week that includes January 1 . The 3-months aggregation is applied also to the atmospheric indices.

Several indices, suited both for spatial and temporal analysis, are then obtained: the mean, maximum and minimum fraction of snow covered area (hereafter referred as indices in space (IS, i.e., $I S_{\text {mean }}, I_{\max }$, and $I S_{\min }$, respectively) are used to investigate the spatial variability; their respective week of occurrence (WO), together with the mean percentage of days with snow (IT, indices of time), are considered as indicators for the temporal variability.

The Mann-Kendall test for trend (Helsel and Hirsch, 1992) is applied to the time series of snow indices in order to detect significant trends in the duration and extent of snow cover. This test is non-parametric and is therefore quite robust, in that it does not assume any prior distribution of the data. Moreover, it is less affected by outliers, because it compares the relative magnitudes of data rather than the data values. Since serial correlation can affect the significance of the trend detected, data are tested for autocorrelation using the LjungBox-Q test (Ljung and Box, 1978) with a significance level equal to 0.05 . When serial correlation is present, the significance of trend is assessed following the procedure described in Hamed and Rao (1998).

The relationships between snow cover and atmospheric circulation indices are investigated using the Spearman Rank correlation test (Helsel and Hirsch, 1992), that gives a nonparametric measure of the statistical dependency between two ranked variables. Correlations and trends are assumed to be statistically significant when their significance level is $\alpha=0.05$. A general assumption of non-parametric tests based on rank is that the sample is drawn from a continuous distribution and that tied observations (i.e. recurrence of the same value) can be ignored. Dealing with snow cover data over the whole Europe, this assumption is not realistic for regions where the variability of temporal indices is either zero (i.e presence or absence of snow cover for the whole seasonal time series) or very low. To overcome this problem, only time series of IT with a coefficient of variation grater than 0.2 are used to perform the correlation and the trend tests. Adopting this threshold over the coefficient of variation as a selection criterion, the IT times series corresponding to areas with low snow cover variability (e.g. South-Western Spain and Southern Italy) are removed from the analyses. However, even when the variability is high, some values of IT can repeatedly occur in the time series. Therefore, a correction for tied observation is considered for the evaluation of the test significance (Helsel and Hirsch, 1992, see chapter 8).

\section{Results}

\subsection{Snow cover variability assessment}

The interannual variability of snow cover is initially assessed by means of trend analysis. A positive (negative) trend of the spatial indices indicates an increase (decrease) in the extent of the snow cover. With regards to the temporal indices, increasing or decreasing tendencies would reveal changes in the snow season length.

For the annual and 6-months IS indices considered no significant trends are detected. For the 3-months aggregation scale, the maximum snow extent shows a positive trend $(\tau=$ 
Table 1. Correlation coefficients between snow cover and atmospheric patterns indices; ${ }^{*}$ indicates a significance level $\alpha=0.05$, other reported coefficient has a significance level of 0.1 .

\begin{tabular}{ccccccc}
\hline & NAO & AO & EA & EA/WR & SCA & POL \\
\hline$I S_{\text {mean,JAN-MAR }}$ & - & $-0.647^{*}$ & 0.292 & - & - & - \\
$I S_{\text {mean,APR-JUN }}$ & - & $-0.382^{*}$ & - & - & - & 0.292 \\
$I S_{\text {mean,JUL-SEP }}$ & $0.334^{*}$ & - & - & - & - & - \\
$I S_{\text {max JAN-MAR }}$ & - & $-0.376^{*}$ & - & - & - & - \\
$I S_{\max , \text { JUL-SEP }}$ & $0.357^{*}$ & - & - & - & - & - \\
$I S_{\max , \text { OCT-DEC }}$ & $0.354^{*}$ & $-0.350^{*}$ & - & - & - & - \\
$I S_{\min , \mathrm{JAN}-\mathrm{MAR}}$ & - & $-0.590^{*}$ & - & - & - & - \\
$I S_{\min , \mathrm{APR}-\mathrm{JUN}}$ & - & - & - & 0.320 & - & - \\
$I S_{\min , \mathrm{JUL}-\mathrm{SEP}}$ & -0.285 & - & - & - & - & - \\
$I S_{\min , \mathrm{OCT}-\mathrm{DEC}}$ & - & - & - & - & - & 0.306 \\
$W O_{\max , \mathrm{JAN}-\mathrm{MAR}}$ & $-0.347^{*}$ & $-0.334^{*}$ & $0.394^{*}$ & - & - & - \\
$W O_{\max , \mathrm{APR}-\mathrm{JUN}}$ & 0.290 & - & - & - & $0.421^{*}$ & - \\
$W O_{\max , \mathrm{JUL}-\mathrm{SEP}}$ & - & - & 0.301 & - & - & - \\
$W O_{\min , \mathrm{JAN}-\mathrm{MAR}}$ & - & - & 0.324 & - & - & - \\
$W O_{\min , \mathrm{APR}-\mathrm{JUN}}$ & - & - & 0.332 & $0.339^{*}$ & - & - \\
$W O_{\min , \mathrm{JUL}-\mathrm{SEP}}$ & 0.313 & - & - & - & - & - \\
$W O_{\min , \mathrm{OCT}-\mathrm{DEC}}$ & - & 0.331 & $0.364^{*}$ & - & $0.432^{*}$ & $0.365^{*}$ \\
\hline
\end{tabular}

0.29) during autumn (October-December) and a negative trend $(\tau=-0.24)$ in the summer season (July-September).

Considering snow cover permanency expressed by the mean percentage of snow-covered days (IT), the Kendall coefficient $\tau$ has significant values in extended areas (see Fig. 1, at the 3-months aggregation) including: i) negative trends in Southern Iceland (April-June, $\tau=-0.44$ ), on the Pyrenees (April-June, $\tau$ from -0.31 to -0.41 ), Atlantic Scandinavian Coast and Western Alps (July-August), with $\tau$ varying in the interval -0.47 to -0.34 ; ii) positive trends above Austria and Czech Republic (October-December, $\tau=0.25-0.37$ ), the Balkan region (October-March, $\tau=0.25-0.66$ ) and Northern Iceland (April-June, $\tau \approx 0.28$ ).

\subsection{Correlation with large scale patterns of climate variability}

We first checked for correlations between IS or WO and the previously-cited modes of climate variability (i.e. AO, NAO, EA, EA/WR, SCA, and POL). The results obtained are reported in Table 1. The winter spatial variability appears to be mainly driven by the Arctic Oscillation, which is negatively correlated with the mean, the maximum and the minimum snow cover extent. This connection persists also during spring, when the effect of the Polar Pattern, with the opposite sign, can be observed. The East Atlantic pattern is positively correlated with winter snow cover, but its significance is smaller. The North Atlantic Oscillation is preferentially related to the summer snow cover (positively with mean and maximum, and negatively with the minimum).

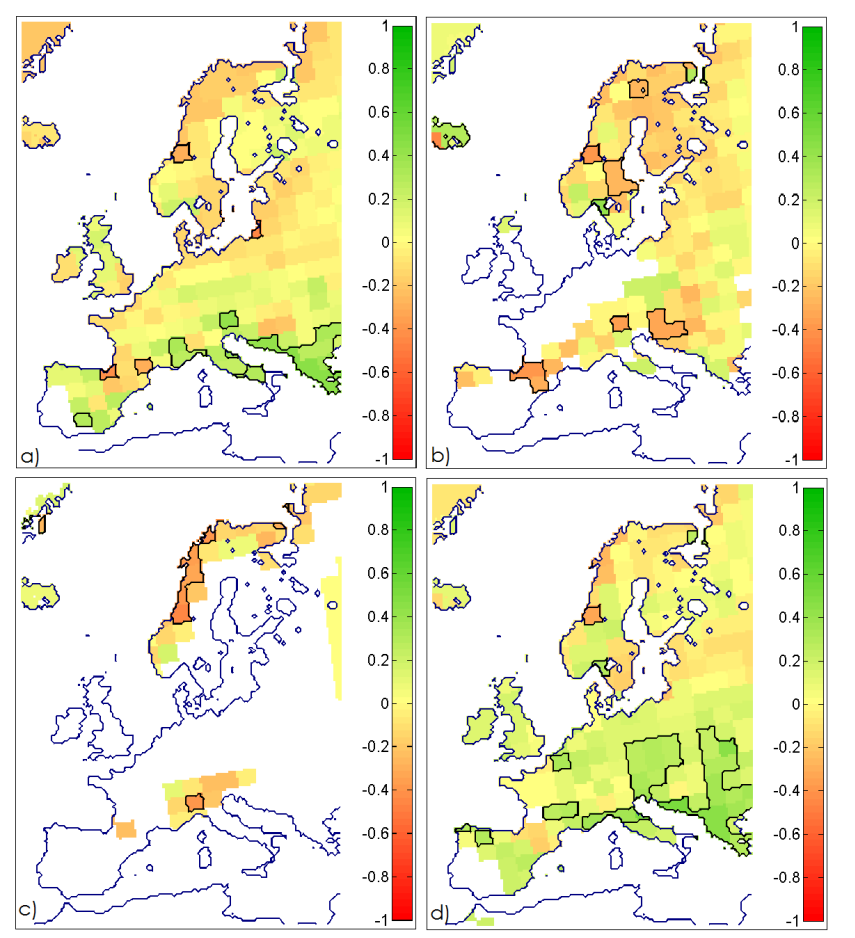

Fig. 1. Spatial representation of 3-months IT climatic trends: (a) January-March; (b) April-June; (c) July-September; (d) OctoberDecember. 


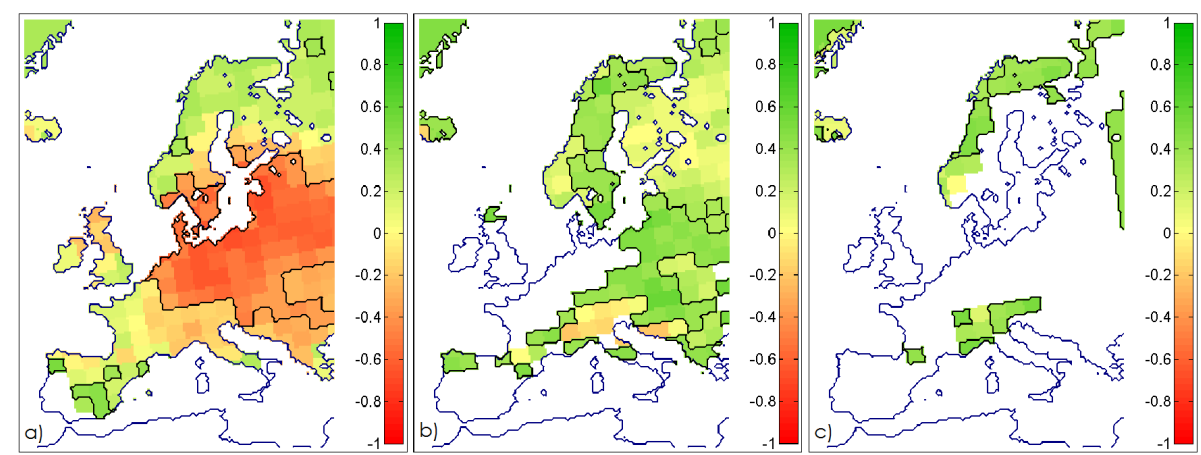

Fig. 2. Spatial representation of the Spearman correlation coefficients between atmospheric and snow covered indices IT. (a) winter AO (January-March); (b) spring EA/WR (April-June); (c) summer NAO (July-September). Black borders identify areas with significant correlation.

With regard to the temporal variability of snow cover extent we observe that the WO index (week of occurrence) of the maximum snow cover extent is negatively correlated with $\mathrm{NAO}, \mathrm{AO}$ and EA for winter, and positively related with $\mathrm{NAO}$ and SCA during spring and with EA during summer. On the contrary, the week of occurrence of the minimum snow cover extent always presents positive correlations with EA (January-June), EA/WR (April-June) and NAO (JulySeptember). During autumn, an interplay of different atmospheric patterns is evident (AO, EA, SCA and POL).

The main areas of influence of each circulation type can be observed when we correlate the temporal indices of mean percentage of snow-covered days (IT) to the modes of climate variability. Wintertime is dominated by the Arctic Oscillation (Fig. 2a), that shows a significant positive correlation for Central Europe. Negative correlation exists, though less spatially extended, with Scandinavia (NAO, EA), Russia (NAO, EA/WR, SCA), Northern France (NAO) and Spain (EA). During spring time, the positive correlation between $\mathrm{AO}$ and snow cover maintains its positive sign over Scandinavia, and becomes positive in the Pyrenees, while other climate patterns (NAO, EA, EA/WR (Fig. 2b) and POL) increase their regions of influences over central Europe. This suggests the existence of a lag between the atmospheric conditions and their effects on snow cover. It is interesting to notice that, even when significant correlation exists over a large part of Europe, the European Alps show a peculiar behavior in that no strong relationship can be found with these modes of climate variability. The only significant correlation between snow cover in this region (Fig. 2c) and the NAO is characterized by negative sign during summer (JulySeptember), while the Oct-Dec period does not exhibit significant correlations.

\section{Conclusions}

The analysis of the interannual variability of snow cover in Europe shows some significant trends with an increase in snow covered area during cold months (October-December) and a decrease in the warm season (July-September). Even if these results are based on a relatively short period of time (1972-2006), they can provide some important indications on trends in the snow regime. Significant trends are also found in some regions of Europe in the duration of snow cover, though the sign of these trends varies with the particular geographic location. Moreover, in the absence of high spatial resolution snow cover data, no conclusion can be drawn at the local scale. Interannual variability of snow cover is related to the Arctic Oscillation during wintertime, while in the other seasons weaker and less significant correlation is found with other patterns of climate variability, such as the NAO and EA/WR. These results indicate a possible strong control of the Arctic Oscillation on the interannual variability of water resources stored in the snow pack and released as stream flow in the snow melt season over large areas in Europe.

Edited by: M. C. Llasat

Reviewed by: one anonymous referee

\section{References}

Adam J. C., Hamlet A. F., and Lettenmaier, D. P.: Implications of global climate change for snowmelt hydrology in the twenty-first century, Hydrol. Process., 23, 962-972, 2009.

Armstrong, R. L. and Brodzik, M. J.: Northern hemisphere EASEGrid weekly snow cover and sea ice extent version 3, National snow and Ice Data Center. Digital Media, Boulder, Colorado, USA, 2005.

Armstrong, R. L. and Brun, E.: Snow and climate: physical processes, surface energy exchange and modeling, Cambridge University Press, Cambridge, UK, 2008. 
Barnston, A. G. and Livezey, R. E.: Classification, seasonality and persistence of low-frequency atmospheric circulation patterns, Mon. Weather Rev., 115, 1083-1126, 1987.

Bartolini, E., Claps, P., and D'Odorico, P.: Interannual variability of winter precipitation in the European Alps: relations with the North Atlantic Oscillation., Hydrol. Earth Syst. Sci., 13, 17-25, doi:10.5194/hess-13-17-2009, 2009.

Bonan, G.: Ecological climatology, Cambridge University Press, Cambridge, UK, 2002.

Brown, R.D.: Northern hemisphere snow cover variability and change, 1915-1997, J.. Climate, 13, 2339-2355, 2000.

Chow, V. T, Maidment, D., Davis, R., and Mays, L. W.: Applied Hydrology, McGraw-Hill, New York, USA, 1998.

Clark, M. P., Serreze, M. C., and Robinson, D. A.: Atmospheric controls on eurasian snow extent, Int. J. Climatol., 19, 27-40, 1999.

Cohen, J. and Entekhabi, D.: The influences of snow cover on northern hemisphere climate variability, Atmos. Ocean., 39(1), 35-53, 2001.

Dingman, S. L.: Physical Hydrology, Prentice Hall, Upper Saddle River, New Jersey, USA, 1994.

Gutzler, D. S. and Rosen, R. D.: Interannual variability of wintertime snow cover across the northern hemisphere, J. Climate, 5, 1441-1447, 1992.
Hamed, K. H. and Rao, A. R.: A modified mann-kendall trend test for autocorrelated data, J. Hydrol., 204, 182-196, 1998.

Helsel, D. R. and Hirsch, R. M.: Statistical methods in water resources, Elsevier, Amsterdam, 1992.

Hurrell, J. W.: Decadal trends in the north atlantic oscillation and relationship to regional temperature and precipitation, Science, 269, 676-679, 1995.

Ljung, G. M. and Box, G. E. P.: On a measure of lack of fit in time series models, Biometrika, 65, 297-303, 1978.

Quality Control Summary for NSIDC's Northern Hemisphere EASE-Grid Weekly Snow Cover and Sea Ice Extent Version 3 data set, http://nsidc.org/data/docs/daac/nsidc0046_nh_ease_ snow_seaice/QC_summar\%y.html, last access: 29 April 2010 , 2007.

Popova, V.: Winter snow depth variability over northern eurasia in relation to recent atmospheric circulation changes, Int. J. Climatol., 27, 1721-1733, 2007.

Thompson, D. W. J. and Wallace, J. M.: Regional climate impacts of the northern hemisphere annular mode, Science, 6, 85-89, 2001.

Yoo, J. and D'Odorico, P.: Trends and fluctuations in the dates of ice breack-up of lakes and rivers in northern europe: the effect of the north atlantic oscillation, J. Hydrol., 268, 100-112, 2002. 